\title{
Asthma treatment in children: A pragmatic approach
}

R Masekela, ${ }^{1} \mathrm{PhD}$; A Jeevanathrum, ${ }^{2}$ Cert Pulmonology (SA) Paed; S Kling ${ }^{3}$ FCPaed (SA), MPhil (Appl Ethics); T C Gray, ${ }^{3}$ Cert Pulmonology (SA) Paed; J Morrison, ${ }^{3}$ Cert Pulmonology (SA) Paed; A Vanker, ${ }^{4}$ Cert Pulmonology (SA) Paed; A S Puterman, ${ }^{5}$ FC Paed (SA); D Rhode, ${ }^{6}$ Cert Pulmonology (SA) Paed; E W Zöllner, ${ }^{3}$ PhD; P de Waal, ${ }^{7}$ MMed (Paed); A I Manjra, ${ }^{8}$ FCPaed (SA), M Clin Pharm; M Levin, ${ }^{4} \mathrm{PhD}$; H Zar, ${ }^{4} \mathrm{PhD}$; R J Green, ${ }^{2} \mathrm{PhD}$, DSc; F E Kritzinger, ${ }^{3,9} \mathrm{Cert}$ Pulmonology (SA) Paed; on behalf of the South African Childhood Asthma Working Group (SACAWG)

\author{
${ }^{1}$ Inkosi Albert Luthuli Central Hospital and Department of Paediatrics and Child Health, School of Clinical Medicine, College of Health Sciences, \\ University of KwaZulu-Natal, Durban, South Africa \\ ${ }^{2}$ Steve Biko Academic Hospital and Department of Paediatrics and Child Health, School of Medicine, Faculty of Health Sciences, \\ University of Pretoria, South Africa \\ ${ }^{3}$ Department of Paediatrics and Child Health, Faculty of Medicine and Health Sciences, Stellenbosch University, Cape Town, South Africa \\ ${ }^{4}$ Department of Paediatrics and Child Health, Red Cross War Memorial Children's Hospital, and Medical Research Council Unit on Child and \\ Adolescent Health, Faculty of Health Sciences, University of Cape Town, South Africa \\ ${ }^{5}$ Private practice, Life Kingsbury Hospital, Cape Town, South Africa \\ ${ }^{6}$ Private practice, Melomed Private Hospital, Cape Town, South Africa \\ ${ }^{7}$ Department of Paediatrics and Child Health, Faculty of Health Sciences, University of the Free State, Bloemfontein, South Africa \\ ${ }^{8}$ Private practice, Life Westville Hospital, Durban, South Africa \\ ${ }^{9}$ Netcare Christiaan Barnard Memorial Hospital, Cape Town, South Africa
}

Corresponding author: R Masekela (masekelar@ukzn.ac.za)

Background. Asthma is a heterogeneous condition characterised by chronic inflammation and variable expiratory airflow limitation, with airway reversibility. Management of chronic inflammation with anti-asthma medication improves asthma control and quality of life. Objectives. To provide an evidence-based approach for chronic asthma management in young children and adolescents and provide guidance on the use of new asthma drugs in children.

Methods. The South African Childhood Asthma Working Group (SACAWG) convened in January 2017. The asthma treatment task group reviewed the available scientific literature and international asthma treatment guidelines. The evidence was then graded according to the Grades of Recommendation Assessment, Development and Evaluation (GRADE) system and recommendations were made based on scientific evidence and local context. Asthma management recommendations were made for children $<6$ years of age and older children and adolescents, as well as for stepping up and stepping down of therapy. This review does not include biologics or novel asthma drugs, which are covered in another CME article in this edition of SAMJ.

Conclusions. To ensure good response, treatment and adherence, type of medication, device and checking of technique are all critical. Stepping up of therapy should be done only after ensuring good adherence and technique. Once therapeutic response is achieved, medication administration has to be stepped down to improve ease of use and avoid unnecessary side-effects.

S Afr Med J 2018;108(8):612-618. DOI:10.7196/SAMJ.2018.v108i8.13164

The South African Childhood Asthma Working Group (SACAWG), a subcommittee of the Allergy Society of South Africa (ALLSA), first published its guideline for the management of chronic asthma in children and adolescents in 1992, followed by revisions in $1994,{ }^{[1]}$ $2000^{[2]}$ and $2009 .{ }^{[3]}$ In the interim, there have been a number of key changes in the diagnostic criteria (particularly in young children, assessment of asthma control, management principles, new drugs and new drug-delivery devices).

Pharmacotherapy is the cornerstone of asthma management. Selection of medication and delivery devices has to meet the patients' needs and characteristics. Periodic assessment of asthma control and review of management are critical to gain control of the disease and limit medication side-effects.

\section{Methods}

SACAWG reconvened in January 2017 with 6 task groups, each headed by a leader (Appendix A), constituting the editorial committee on assessment of asthma epidemiology, diagnosis, control, treatments, novel treatments and self-management plans. The asthma medication task groups were charged with the responsibility of reviewing the available scientific literature and assigning evidence levels according to the methodology used in current guideline documents. PubMed and Google Scholar searches were done to review the current level of evidence since the publication of the previous guideline. ${ }^{[3]}$ The level of evidence and key recommendations were graded (Appendix B) according to the Grades of Recommendation Assessment, Development and Evaluation (GRADE) system. After completion of each sub-section, it was sent to the entire working group for review, comment and revision. Any disagreements or inconsistencies were dealt with via round robin, with a majority recommendation based on the evidence if there was disagreement.

\section{Assessment of severity to initiate therapy}

The method of assessment conforms to international assessment criteria. The assessment of severity is used to assign a child to a particular treatment group as a starting point. This assessment refers to a child's symptoms and lung function (peak expiratory flow (PEF) 
or forced expiratory flow in 1 second $\left.\left(\mathrm{FEV}_{1}\right)\right)$ between acute episodes if they are not receiving long-term therapy (Table 1). Severity can also be measured once asthma control is achieved by the step of care (i.e. various medications) required to maintain control. One or more features must be present to assign a severity grading to the most severe grade in which any feature occurs.

\section{Principles of medication}

When selecting medication for an asthmatic patient, the following principles apply: regular anti-inflammatory medication is indicated for persistent asthma, but inhaled therapy is preferable, especially inhaled bronchodilators and inhaled steroids.

Drugs are classified as:

- Relievers (bronchodilators) for acute relief from symptoms, including inhaled short-acting beta ${ }_{2}$-agonists (SABAs) (evidence level I) and anticholinergics. Short-acting xanthines are not recommended in the maintenance treatment of asthma. Anticholinergics are less potent, have a slower onset of action (30 - 60 minutes) and can be used during exacerbations.

- Controllers (anti-inflammatory drugs) for long-term control may modify airway inflammation that is characteristic of asthma.
Inhaled corticosteroids (ICSs) are the most effective controller therapy for asthma (evidence level I). Leukotriene receptor antagonists (LTRAs) are anti-inflammatories that exert their effects via different pathways than ICSs. Long-acting beta ${ }_{2}-$ agonists (LABAs) have weak anti-inflammatory effects. Slowrelease theophyllines also have weak anti-inflammatory effects at lower doses than those required for bronchodilation.

A number of different ICS preparations are available in South Africa (SA) (Tables 2 and 3). ICSs are usually administered twice daily, but budesonide and ciclesonide (registered only for children $>12$ years old) are approved for once-daily use in children with mild asthma. Most children $>5$ years of age are controlled on low daily doses of ICSs (100 - $200 \mu \mathrm{g}$ budesonide or equivalent). Wheezing caused by viral infections is very common in children $<2$ years of age and often resolves spontaneously or remits with increasing age. ICSs should only be used if symptoms are particularly troublesome, and if there is a need for admission and oxygen therapy, with a clear response to treatment. Most importantly, the administration of ICSs should be discontinued if there is no response or a poor response.

Table 1. Classification of asthma severity based on symptoms and lung function (presenting for the first time without treatment)

\begin{tabular}{lllll}
\hline Classification & Mild intermittent & Mild persistent & Moderate persistent & Severe persistent \\
\hline Symptoms & $\leq 2 /$ week & $>2 /$ week & Daily & Continual \\
Night-time symptoms & $\leq 1 /$ month & $>1 /$ month & $>1 /$ week & $>60-\leq 80$ \\
PEF (predicted), \% & $\geq 80$ & $\geq 80$ & $>30$ & Frequent \\
PEFR variability, \%* & $<20$ & $20-30$ & & $>30$ \\
$\begin{array}{l}\text { PEF = peak expiratory flow; PEFR = peak expiratory flow rate. } \\
{ }^{*} \text { Applicable to children }>5 \text { years old. }\end{array}$ & & &
\end{tabular}

Table 2. Preferred low-dose ICS in children $<5$ years old ${ }^{\star}$

\begin{tabular}{|c|c|}
\hline ICS & $\begin{array}{l}\text { Total daily inhaled } \\
\text { dose, } \mu \mathrm{g}\end{array}$ \\
\hline Beclomethasone dipropionate (HFA) & 100 \\
\hline Budesonide (pMDI and spacer) ${ }^{\dagger}$ & 200 \\
\hline Budesonide (nebulised) ${ }^{\dagger}$ & 500 \\
\hline Fluticasone propionate (HFA) & 100 \\
\hline \multicolumn{2}{|c|}{$\begin{array}{l}\text { ICS = inhaled corticosteroid; HFA = hydrofluoroalkane; pMDI = pressurised metered-dose } \\
\text { inhaler. } \\
\text { *Adapted from Global Initiative for Asthma. } \\
\text { "Most preparations are registered for twice-daily use, except budesonide, which may be } \\
\text { administered once daily. }\end{array}$} \\
\hline
\end{tabular}

LABAs should only be used in combination with an ICS. LABAs are primarily indicated as add-on therapy in children $>5$ years of age, whose asthma is not controlled by moderate doses of ICSs (evidence level II) (Table 4).

LTRAs have a rapid onset of action ( $1-3$ hours) and are taken once a day. They are available in $5 \mathrm{mg}$ tablets, $4 \mathrm{mg}$ chewable tablets and $4 \mathrm{mg}$ oral granule formulations. Because of easy administration (compared with inhaler devices) and once-daily dosing, patients are often adherent to LTRAs only. It should be noted and explained to parents that LTRAs are not the preferred first-line treatment for asthma. LTRAs have been shown to be inferior to ICSs with regard

Table 3. Estimated equipotent daily dosage of ICS for children 6 - 11 years old

\begin{tabular}{|c|c|c|c|}
\hline Drug & Low daily dose, $\mu \mathrm{g}$ & Medium daily dose, $\mu \mathrm{g}$ & High daily dose, $\mu \mathrm{g}$ \\
\hline Beclomethasone dipropionate CFC & $100-200$ & $200-400$ & $>400$ \\
\hline Budesonide DPI & $100-200$ & $200-400$ & $>400$ \\
\hline Ciclesonide HFA* & 80 & $80-160$ & $>160$ \\
\hline Fluticasone propionate $\mathrm{HFA}^{\dagger}$ & $100-200$ & $200-500$ & $>500$ \\
\hline Mometasone furoate & 110 & $220-<440$ & $\geq 440$ \\
\hline \multicolumn{4}{|c|}{ Adolescents ( $\geq 12$ years old) } \\
\hline Beclomethasone dipropionate HFA & $100-200$ & $>200-400$ & $>400$ \\
\hline Budesonide DPI & $200-400$ & $>400-800$ & $>800$ \\
\hline Ciclesonide HFA & $80-160$ & $>160-320$ & $>320$ \\
\hline Fluticasone propionate $\mathrm{HFA}^{\dagger}$ & $100-250$ & $>250-500$ & $>500$ \\
\hline Fluticasone furoate ${ }^{\ddagger}$ & - & - & - \\
\hline Mometasone furoate & $110-220$ & $>220-440$ & $>440$ \\
\hline
\end{tabular}


Table 4. Combination products available in South Africa

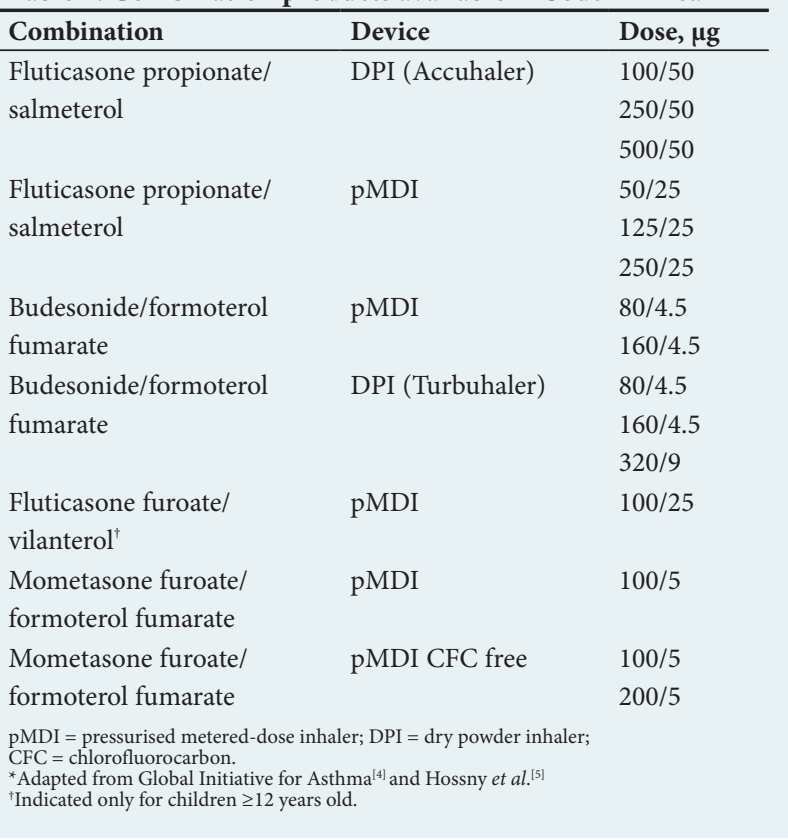

to symptom improvement, exacerbation decrease and hospitalisation frequency in the treatment of asthma in the preschool child. This medication may be used as add-on therapy in children $>5$ years of age, whose asthma is insufficiently controlled by low doses of ICSs (evidence level II), or as alternative first-line therapy to ICSs for episodic or mild persistent asthma in children $<5$ years old (evidence level II).

Theophylline may be used as add-on therapy in more severe asthma that is not controlled with ICSs in children $>12$ years of age and in adults (evidence level IV), but safety concerns preclude its recommendation.

Oral corticosteroids should only be used for acute asthma exacerbations, preferably only in hospitalised patients and for a maximum of 3 days at $0.5-1 \mathrm{mg} / \mathrm{kg} /$ dose of prednisone given once daily. For children $<5$ years old, these are only recommended in exacerbations that require hospitalisation.

\section{Routes of administration Inhaled medications}

Inhaled therapy is the cornerstone of asthma treatment for all children. Most children can be taught to use inhaled therapy effectively. Different age groups require different inhaler devices together with a pressurised metered-dose inhaler (pMDI) with or without a holding chamber (spacer). The alternative is a dry powder metered-dose inhaler (DPI) (Box 1). Considerations when choosing an inhaler device include the efficacy of drug delivery, cost, safety, ease of use, convenience and efficacy in a specific age group. ${ }^{[5]} \mathrm{A}$ pMDI with holding chamber (spacer) is preferable to nebulised therapy owing to convenience, more effective lung deposition, fewer side-effects and lower cost. ${ }^{[6-8]}$ The technique for each device type varies, has to be correct for optimal drug delivery and should be checked at each visit (Box 2).

\section{Valved holding chamber (spacer)}

Valved holding chambers allow inhalation at a normal respiratory rhythm even without synchronising actuation and inhalation, thus increasing inhalation efficiency. Spacers also retain large drug particles that would otherwise be deposited in the oropharynx.

\begin{tabular}{ll}
\multicolumn{2}{l}{ Box 1. Choice of inhaler device for children } \\
\hline Age group, years & Preferred device \\
\hline$<4$ & pMDI and spacer with face mask \\
$4-6$ & pMDI and spacer with mouthpiece \\
$>6$ & $\begin{array}{l}\text { Dry powder inhaler, or pMDI with spacer } \\
\text { and mouthpiece or breath-actuated pMDI }\end{array}$ \\
& pMDI = pressurised metered-dose inhaler.
\end{tabular}

Box 2. Correct use of pressurised metered-dose inhaler and holding chamber (spacer)

Assemble spacer, remove mouthpiece cover from the pMDI, and attach MDI

Shake canister vigorously for $5 \mathrm{~s}$, then hold assembled canisterspacer/chamber in a horizontal position

Breathe out normally

Place mouthpiece of spacer/chamber into mouth and close lips around mouthpiece

At the start of the next inhalation, actuate the pMDI

Keep inhaling deeply and slowly through your mouth. If you

hear a whistling sound from the chamber, slow down the rate of inhalation

Hold your breath for $5-10 \mathrm{~s}$. Then breathe out slowly and gently Wait 15 - 30 s before you give the second puff, if required. Shake the inhaler again before the second puff

If the inhaler is a steroid medicine, rinse out your mouth, gargle, and spit out the water

Remove the pMDI from spacer/chamber and replace the mouthpiece cover

pMDI = pressurised metered-dose inhaler.

If the spacer has a facemask, hold the latter snugly over the child's mouth and nose.
In a young child who cannot follow instructions, press the pMDI at the start of a slow

breath in and keep mask firmly in place for $5-6$ breaths.

This reduces oropharyngeal side-effects, systemic absorption and bio-availability of inhaled drug. It is especially important for ICSs with first-pass metabolism, such as beclomethasone and budesonide.

\section{Nebulisers}

A pMDI with a spacer is as effective as, or more effective than, nebulised treatment for acute, severe asthma exacerbation. ${ }^{[8,9]}$ Nebulisers have imprecise dosing, are expensive and waste large amounts of drug into the surrounding air. For home use, nebulisers are discouraged; they should be restricted to cases where oxygen administration is necessary and available (evidence level I).

\section{Dry powder inhaler}

A DPI is a breath-actuated device containing micronised drug particles with a mass median aerodynamic diameter of $<5 \mu \mathrm{m}$. ${ }^{[10,11]}$ DPI devices eliminate the requirement for propellants, as well as for co-ordination between inhalation and device actuation. The disadvantage of DPIs is the high inspiratory flow rates $(30-120 \mathrm{~L} /$ $\mathrm{min})$ that are required to aerosolise the drug. ${ }^{[1,12]}$ In one study, the age at which most children who were inexperienced in the use of a DPI could generate a peak inspiratory flow rate of $\geq 30 \mathrm{~L} / \mathrm{min}$ was 4 years, and the age at which most children could generate a peak inspiratory flow rate of $\geq 60 \mathrm{~L} / \mathrm{min}$ was 9 years. ${ }^{[12]}$ Furthermore, the rapid inhalation required to ensure optimal lung deposition might be confusing for children who use both an MDI and a DPI. It should be noted that equivalent doses for these devices also differ. 


\section{Treatment options}

Before stepping up of treatment, symptom control, steroid sideeffects and comorbid conditions (e.g. allergic rhinitis) must be assessed. Ensure adequate patient education (e.g. inhaler skills, adherence and written asthma action plan). Assess environmental exposure to allergens and irritants, especially tobacco smoke. Consider the possibility of an alternative diagnosis, poor adherence to treatment or incorrect inhaler technique. Do not step up treatment unless the abovementioned problems have been addressed (Tables 5 and 6).

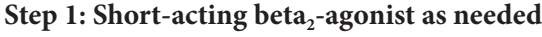

In the case of mild symptoms (not requiring oral corticosteroids and hospital admission with supplemental oxygen), a SABA with a dedicated spacer device, facemask and an adequate technique are indicated. This treatment is reserved for infrequent symptoms and will not prevent future exacerbations.

Table 5. Asthma treatment options for children 2 - 5 years of age

\begin{tabular}{lc}
\hline & Step 1 \\
\hline Intermittent reliever therapy & SABA as needed \\
& Step 2 \\
\hline Low-dose controller and & Low-dose ICS \\
as-needed reliever medication & $\begin{array}{l}\text { Intermittent ICS (second } \\
\text { choice if seasonal symptoms) }\end{array}$ \\
& LTRA \\
& Step 3 \\
\hline Additional controller and & Medium-dose ICS \\
as-needed reliever medication & Low-dose ICS and LTRA \\
& Step 4 \\
\hline
\end{tabular}

Refer to specialist (paediatrician, paediatric allergologist or paediatric pulmonologist)

SABA $=$ short-acting beta ${ }_{2}$-agonist; ICS $=$ inhaled corticosteroid; LTRA $=$ leukotriene receptor antagonist.

Table 6. Asthma treatment options for children $\geq 6$ years old

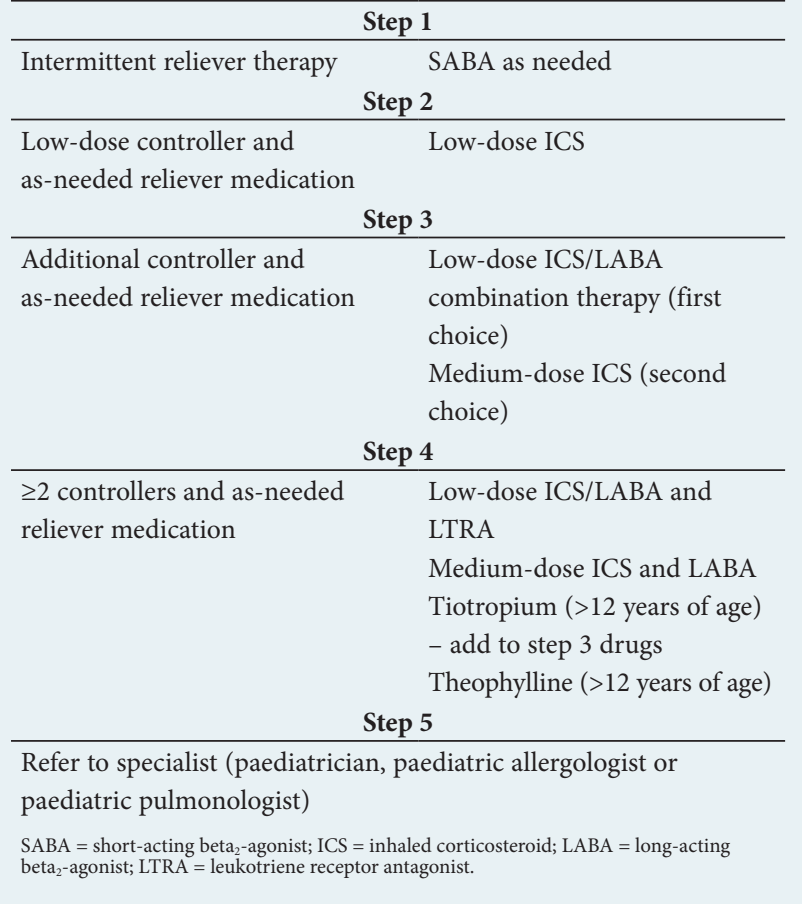

ICSs should be considered for patients with any of the following asthma-related features: ${ }^{[14-16]}$

- an asthma attack in the past 2 years, requiring the use of bronchodilators and systemic steroids

- using inhaled SABAs $\geq 3$ times a week

- symptomatic $\geq 3$ times a week

- nocturnal waking $\geq 1$ times a week.

Step 2: Low-dose controller medication and as-needed reliever medication

In all children the preferred option is regular low-dose ICSs, which are the most effective preventer drugs for adolescents and older children for achieving overall treatment goals (evidence level I). ${ }^{[13-15]}$ Treatment with low-dose ICSs reduces asthma symptoms, improves lung function and quality of life, and reduces the risk of exacerbations, asthma-related hospitalisations and death (evidence level I). ${ }^{[13,17,18]}$

\section{Alternative options}

In young children with recurrent viral-induced wheezing, regular LTRAs improve some asthma outcomes compared with placebo, but do not reduce the frequency of hospitalisation, courses of prednisone, or number of symptom-free days (evidence level I). As an alternative, LTRAs have some beneficial clinical effects and may be used as initial controller treatment in children unable or unwilling to use ICSs, for patients who experience intolerable side-effects from ICSs or for those with concomitant allergic rhinitis (evidence level II). ${ }^{[19-23]}$

\section{Intermittent inhaled corticosteroids}

For patients with purely seasonal allergic asthma, with no intercurrent asthma symptoms, ICSs should be started immediately when symptoms commence and continued for 4 weeks after the relevant pollen season ends (evidence level IV). Daily ICSs are superior to intermittent ICSs in several indicators of lung function, airway inflammation, asthma control and reliever use. The strength of the evidence means that, currently, equivalence cannot be assumed between the two options and therefore it is recommended to use daily ICSs (evidence level I). ${ }^{[24]}$

\section{Step 3: Add an additional controller and as-needed reliever medication}

A poor response to low-dose ICSs should be escalated to mediumdose ICSs with as-needed SABAs as the preferred treatment option. In children $<6$ years of age an alternative treatment is mediumdose ICSs or the addition of an LTRA. As an alternative choice, a low-dose ICS/LABA combination with an as-needed SABA can be administered to children $>6$ years old. To date, evidence shows that the outcomes of these two treatments are similar. ${ }^{[25,26]}$ However, meta-analyses demonstrated a trend towards increased risk of exacerbations requiring rescue therapy and hospitalisation with ICS/ LABA treatment in children $<12$ years compared with mediumdose ICSs (evidence level I). ${ }^{[24-26]}$ Based on this, it is currently recommended to escalate therapy to medium-dose ICSs as the preferred choice in this age group.

For children $\geq 12$ years of age, the first choice is adding a LABA to a low-dose ICS. There are two strategies for doing this. The traditional approach of combination ICS/LABA therapy with as-needed SABA reliever therapy is well proven to improve asthma control rather than ICSs alone (evidence level I). ${ }^{[27]}$ The more recent approach of ICS/formoterol maintenance and reliever therapy (or single-inhaler therapy) may, however, be preferable to traditional fixed-dose ICS/ LABA therapy. Studies comparing the two demonstrate a reduced daily 
Box 3. Options for stepping-down treatment in well-controlled asthma*

\begin{tabular}{|c|c|c|c|}
\hline Current step & Current medication and dose & Options for stepping down & Evidence level \\
\hline \multirow[t]{4}{*}{ Step 4} & Moderate- to high-dose ICS/LABA & $\begin{array}{l}\text { Continue ICS/LABA with } 50 \% \text { reduction in ICS } \\
\text { component }\end{array}$ & II \\
\hline & & $\begin{array}{l}\text { Discontinuation of LABA is more likely to lead to } \\
\text { deterioration }^{[40]}\end{array}$ & I \\
\hline & $\begin{array}{l}\text { Medium-dose ICS/formoterol as } \\
\text { maintenance and reliever }\end{array}$ & $\begin{array}{l}\text { Reduce maintenance ICS/formoterol to low dose, } \\
\text { continue as needed with low-dose ICS/formoterol } \\
\text { reliever }\end{array}$ & IV \\
\hline & High-dose ICS and second controller & $\begin{array}{l}\text { Reduce ICS dose by } 50 \% \text { and continue } \\
\text { controller }^{[41]}\end{array}$ & II \\
\hline \multirow[t]{4}{*}{ Step 3} & Low-dose ICS/LABA & Reduce ICS/LABA to once-daily dosing & IV \\
\hline & $\begin{array}{l}\text { Low-dose ICS/formoterol as } \\
\text { maintenance and reliever }\end{array}$ & $\begin{array}{l}\text { Discontinuation of LABA is more likely to lead to } \\
\text { deterioration }^{[40]}\end{array}$ & I \\
\hline & & $\begin{array}{l}\text { Reduce maintenance ICS/formoterol dose to once } \\
\text { daily and continue as needed with low-dose ICS/ } \\
\text { formoterol reliever }\end{array}$ & III \\
\hline & Moderate- or high-dose ICS & Reduce ICS dose by $50 \%{ }^{[41]}$ & I \\
\hline \multirow[t]{2}{*}{ Step 2} & Low-dose ICS & $\begin{array}{l}\text { Once-daily dosing (budesonide, ciclesonide, } \\
\text { mometasone) }\end{array}$ & I \\
\hline & Low-dose ICS or LTRA & $\begin{array}{l}\text { Consider stopping controller treatment if no } \\
\text { symptoms for } 6 \text { - } 12 \text { months and no risk factors }\end{array}$ & IV \\
\hline
\end{tabular}

dose of ICS and a reduced exacerbation rate requiring oral steroids or hospitalisation in the former group (evidence level I). ${ }^{[27-31]}$ Of particular importance is that in any age group LABAs should never be used alone and should only be used in combination with an ICS.

The addition of slow-release theophylline to a low-dose ICS has a similar effect as an increase from low- to medium/high-dose ICS (evidence level II). ${ }^{[32]}$

Step 4: Two or more controllers and as-needed reliever medication Other options in this group are switching to high-dose ICSs and adding a second controller, or adding a third controller to a failing medium-dose ICS/LABA regimen. Tiotropium administered by means of a mist inhaler has been demonstrated to improve asthma control in patients who receive medium-dose ICS/LABA therapy and was non-inferior to adding salmeterol to medium/high-dose steroid monotherapy in severe asthma (evidence level I). ${ }^{[33]}$ Similarly, the addition of an LTRA ${ }^{[34-37]}$ (evidence level II) or slow-release theophylline ${ }^{[70]}$ (evidence level II) is efficacious in improving asthma control in severe asthmatics.

Of note is that ICSs have a relatively flat dose-response curve. The main benefits appear to be gained from the use of low- to medium-dose steroids. An increase to high-dose steroids confers little advantage, at the expense of greater side-effects (evidence level I) ${ }^{[38,39]}$ Hence, it is generally preferable to add a second or third controller to a failing regimen than increasing the steroid burden.

\section{Step 5: Refer}

All children with severe asthma who fail appropriate therapy should be referred to a paediatrician, paediatric allergologist or paediatric pulmonologist for further management, also to confirm the diagnosis and exclude aggravating comorbidities.

\section{Stepping-down treatment}

Stepping-down treatment should be considered once good asthma control has been achieved and maintained for 3 months and lung function has reached a plateau (evidence level IV). Any stepdown treatment depends on patient characteristics, as only a few step-down studies have been performed in children. Approach each step as a therapeutic trial. Provide clear instructions and an asthma action plan. Monitor symptoms and/or PEF and schedule a follow-up visit. Stepping down ICS doses by $25-50 \%$ at 3 -month intervals is feasible and safe for most patients (evidence level I). When stepping down to once-daily dosing, it should preferably be a morning dose. Box 3 summarises step-down strategies for different controller treatments.

\section{Conclusion}

To ensure a good response from treatment and adherence, the type of medication, device and checking of technique are critical. Stepping up of therapy should be done only after ensuring good adherence and technique. Once therapeutic response is achieved, medication has to be stepped down to improve ease of medication use and avoid unnecessary side-effects.

Acknowledgements. We would like to acknowledge the hard work and contribution of the South African Childhood Asthma Working Group (SACAWG) members. We also acknowledge the huge contribution of the late Prof. Cas Motala, who was convener of the past three SACAWG guideline groups. The current guideline was sent to external reviewers and for comment from the Department of Health (Drs Gavin Steele and Jane Ridden) and members of the Allergy Society of South Africa.

Author contributions. RM: review, write-up and manuscript writing and editing; FEK, AJ, SK, JM, ASP, DR, PdW, EWZ, TCG, AV: conceptualisation, review, write-up and manuscript editing; and HZ, ML, RJG, AIM: write-up and manuscript editing.

Funding. SACAWG conducted a workshop that received an unconditional educational grant from the Allergy Society of South Africa - funded by Novartis. 
Conflicts of interest. RM: advisory board for AstraZeneca and AbbVie, and speaker for Cipla, AstraZeneca, AbbVie and Norvartis. FEK, AJ, SK, JM, ASP, DR, PdW, EWZ, HZ, ML and AIM: none. RJG: advisory board and speaker bureau for AstraZeneca, Aspen/GSK, Cipla, MSD and Novartis.

1. South African Childhood Asthma Working Group. Management of chronic childhood and adolescent asthma - 1994 consensus. S Afr Med J 1994;84(12):862-866

2. South African Childhood Asthma Working Group. Guideline for the management of chronic asthma in children - 2000 update. S Afr Med J 2000;90(5):524-539.

in children - 2000 update. S Afr Med J 2000;90(5):524-539. South African Childhood Asthma Working Group. Mange asthma - 2009 update. S Afr Med J 2009;9(12):898-912.

4. Global Initiative for Asthma. www.ginasthma.org (accessed 22 January 2017).

. Hossny E, Rosario N, Lee BW, et al. The use of inhaled corticosteroids in pediatric asthma: Update. World Allergy Organ J 2016;9:26. https://doi.org/10.1186/s40413-016-0117-0

6. Pedersen S. Inhalers and nebulizers: Which to choose and why. Respir Med 1996;90(2):69-77. https:// doi.org/10.1016/S0954-6111(96)90201-2

7. Cates CJ, Crilly JA, Rowe BH. Holding chambers (spacers) versus nebulisers for beta-agonist treatmen of acute asthma. Cochrane Database Syst Rev 2006;(2):CD000052. https://doi.org/10.1002/14651858. CD000052.pub2

8. Castro-Rodriguez JA, Rodrigo GJ. Beta-agonists through metered-dose inhaler with valved holding chamber versus nebulizer for acute exacerbation of wheezing or asthma in children under 5 years of age: A systematic review with meta-analysis. J Pediatr 2004;145(2):172-177. https://doi.org/10.1016/ jpeds.2004.04.007

9. Cates CJ, Welsh EJ, Rowe BH. Holding chambers (spacers) versus nebulisers for beta-agonist treatment of acute asthma. Cochrane Database Syst Rev 2013;(9):CD000052. https://doi.org/10.1002/14651858 CD000052.pub3

10. Fink JB. Aerosol device selection: Evidence to practice. Respir Care 2000;45(7):874-885.

11. Dhand R. Aerosol therapy for asthma. Curr Opin Pulm Med 2000;6(1):59-70. https://doi. org/10..1097/00063198-200001000-00012

12. Amirav I, Newhouse MT, Mansour Y. Measurement of peak inspiratory flow with in-check dial device to simulate low-resistance (Diskus) and high-resistance (Turbohaler) dry powder inhalers in children with asthma. Pediatr Pulmonol 2005;39(5):447-451. https://doi.org/10.1002/ppul.20180

13. Adams N, Bestall JM, Lasserson TJ, Jones PW. Inhaled fluticasone versus inhaled beclomethasone or inhaled budesonide for chronic asthma in adults and children. Cochrane Database Syst Rev or inhaled budesonide for chronic asthma in adults and children.
2005;(2):CD002310. https://doi.org/10.1002/14651858.CD002310.pub2

14. Adams NP, Bestall JB, Malouf R, Lasserson TJ, Jones PW. Inhaled beclomethasone versus placebo for chronic asthma. Cochrane Database Syst Rev 2005;(1):CD002738. https://doi.org/10.1002/14651858. CD002738.pub2

15. Calpin C, Macarthur C, Stephens D, Feldman W, Parkin PC. Effectiveness of prophylactic inhale steroids in childhood asthma: A systemic review of the literature. J Allergy Clin Immuno 1997;100(4):452-457. https://doi.org/10.1016/S0091-6749(97)70134-9

16. O'Byrne PM, Barnes PJ, Rodriguez-Roisin R, et al. Low dose inhaled budesonide and formoterol in mild persistent asthma: The OPTIMA randomized trial. Am J Respir Crit Care Med 2001;164(8):13921397. https://doi.org/10.1164/ajrccm.164.8.2104102

17. Pauwels RA, Pedersen S, Busse WW, et al. Early intervention with budesonide in mild persisten asthma: A randomised, double-blind trial. Lancet 2003;361(9363):1071-1076. https://doi.org/10.1016/ S0140-6736(03)12891-7

18. Suissa S, Ernst P, Benayoun S, Baltzan M, Cai B. Low-dose inhaled corticosteroids and the prevention of death from asthma. N Engl J Med 2000;343(5):332-336. https://doi.org/10.1056 NEJM200008033430504

19. Ducharme FM. Inhaled glucocorticoids versus leukotriene receptor antagonists as single agent asthm treatment: Systematic review of current evidence. BMJ 2003:326(7390):621. https://doi.org/10.1136 bmi. 326.7390 .621

20. Knorr B, Franchi LM, Bisgaard H, et al. Montelukast, a leukotriene receptor antagonist, for the treatment of persistent asthma in children aged 2 to 5 years. Pediatrics 2001;108(3):e48. https://doi org/10.1542/peds.108.3.e4

1. Philip G, Nayak AS, Berger WE, et al. The effect of montelukast on rhinitis symptoms in patient with asthma and seasonal allergic rhinitis. Curr Med Res Opin 2004;20(10):1549-1558. https://doi. org/10.1185/030079904X3348
22. Valovirta E, Boza ML, Robertson CF, et al. Intermittent or daily montelukast versus placebo for episodic asthma in children. Ann Allergy Asthma Immunol 2011:106(6):518-526. https//doi org/10.1016/janai2011.01.017

23. Wilson AM, Dempsey OJ, Sims EJ, Lipworth BJ. A comparison of topical budesonide and oral montelukast in seasonal allergic rhinitis and asthma. Clin Exp Allergy 2001;31(4):616-624. https://doi. $\mathrm{rg} / 10.1046 / j .1365-2222.2001 .01088 . x$

24. Ni Chroinin M, Greenstone I, Lasserson TJ, Ducharme FM. Addition of inhaled long-acting betaagonists to inhaled steroids as first line therapy for persistent asthma in steroid-naive adults and hildren. Cochrane Database Syst Rev 2009;(4):CD005307. https://doi.org/10.1002/14651858.CD005307.pub2

25. Verberne AA, Frost C, Duiverman EJ, Grol MH, Kerrebijn KF, and the Dutch Asthma Study Group. Addition of salmeterol versus doubling the dose of beclomethasone in children with asthma. Am J Respir Crit Care Med 1998;158(1):213-219. https://doi.org/10.1164/airccm.158.1.9706048

26. Ducharme FM, Ni Chroinin M, Greenstone I, Lasserson TJ. Addition of long-acting beta-agonists to inhaled steroids versus higher dose inhaled steroids in adults and children with persistent asthma. Cochrane Database Syst Rev 2010;(4):CD005533. https://doi.org/10.1002/14651858.CD005533.pub2

27. Kew KM, Karner C, Mindus SM, Ferrara G. Combination formoterol and budesonide as maintenance and reliever therapy versus combination inhaler maintenance for chronic asthma in adults and hildren. Cochrane Database Syst Rev 2013;(12):CD009019. https://doi.org/10.1002/14651858. D009019.pub2

28. Bateman ED, Harrison TW, Quirce S, et al. Overall asthma control achieved with budesonide/ formoterol maintenance and reliever therapy for patients on different treatment steps. Respir Res 2011;12:38. https://doi.org/10.1186/1465-9921-12-38

29. Cates CJ, Karner C. Combination formoterol and budesonide as maintenance and reliever therapy versus current best practice (including inhaled steroid maintenance), for chronic asthma in adults and children. Cochrane Database Syst Rev 2013;(4):CD007313. https://doi.org/10.1002/14651858.CD007313.pub3

30. Papi A, Corradi M, Pigeon-Francisco C, et al. Beclometasone-formoterol as maintenance and reliever treatment in patients with asthma: A double-blind, randomised controlled trial. Lancet Respir Med 2013;1(1):23-31. https://doi.org/10.1016/\$2213-2600(13)70012-2

31. Patel M, Pilcher J, Pritchard A, et al. Efficacy and safety of maintenance and reliever combination budesonide-formoterol inhaler in patients with asthma at risk of severe exacerbations: A randomised controlled trial. Lancet Respir Med 2013;1(1):32-42. https://doi.org/10.1016/S2213-2600(13)70007-9

2. Evans DJ, Taylor DA, Zetterstrom O, Chung KF, O'Connor BJ, Barnes PJ. A comparison of low-dose inhaled budesonide plus theophylline and high-dose inhaled budesonide for moderate asthma. N Engl J Med 1997;337(20):1412-1418. https://doi.org/10.1056/NEJM199711133372002

33. Rodrigo GJ, Castro-Rodriguez JA. What is the role of tiotropium in asthma?: A systematic review with meta-analysis. Chest 2015;147(2):388-396. https://doi.org/10.1378/chest.14-1698

34. Lofdahl CG, Reiss TF, Leff JA, et al. Randomised, placebo controlled trial of effect of a leukotriene receptor antagonist, montelukast, on tapering inhaled corticosteroids in asthmatic patients. BMJ 1999;319(7202):87-90. https://doi.org/10.1136/bmj.319.7202.87

35. Price DB, Hernandez D, Magyar P, et al. Randomised controlled trial of montelukast plus inhaled budesonide versus double dose inhaled budesonide in adult patients with asthma. Thorax 2003;58(3):211-216. https://doi.org/10.1136/thorax.58.3.211

36. Tamaoki J, Kondo M, Sakai N, et al., and the Tokyo Joshi-Idai Asthma Research Group. Leukotriene antagonist prevents exacerbation of asthma during reduction of high-dose inhaled corticosteroid. Am J Respir Crit Care Med 1997;155(4):1235-1240. https://doi.org/10.1164/ajrccm.155.4.9105060

37. Virchow IC, Ir, Prasse A, Naya I, Summerton L, Harris A. Zafirlukast improves asthma control in patients receiving high-dose inhaled corticosteroids. Am J Respir Crit Care Med 2000;162(2):578-585. https://doi.org/10.1164/ajrccm.162.2.990504138

38. Sorkness CA, Lemanske RF, Jr, Mauger DT, et al. Long-term comparison of 3 controller regimens for mild-moderate persistent childhood asthma. The Pediatric Asthma Controller Trial. J Allergy Clin Immunol 2007;119(1):64-72. https://doi.org/10.1016/j.jaci.2006.09.042

39. Powell H, Gibson PG. Inhaled corticosteroid doses in asthma: An evidence-based approach. Med J Aust 2003;178(5):223-225.

40. Brozek JL, Kraft M, Krishnan JA, et al. Long-acting beta ${ }_{2}$-agonist step-off in patients with controlled asthma. Arch Intern Med 2012;172(18):1365-1375. https://doi.org/10.1001/archinternmed.2012.3250

11. Hagan JB, Samant SA, Volcheck GW, et al. The risk of asthma exacerbation after reducing inhaled corticosteroids: A systematic review and meta-analysis of randomized controlled trials. Allergy 2014;69(4):510-516. https://doi.org/10.1111/all.12368

Accepted 7 May 2018

\section{Appendix A. The SA Childhood Asthma Working Group (SACAWG) \\ Epidemiology: H Zar (leader), Western Cape; C Gray, Western Cape.}

Diagnosis of asthma: R Masekela (leader), KwaZulu-Natal; S M Risenga, Limpopo; O P Kitchin, Gauteng; P Goussard, Western Cape.

Assessment of asthma control: R J Green (leader), Gauteng; A van Niekerk, Gauteng; D White, Gauteng; G Davis, Gauteng.

Pharmacotherapy: F E Kritzinger (leader), Western Cape; A Jeevanathrum, Gauteng; P de Waal, Free State; S Kling, Western Cape; A Vanker, Western Cape; T C Gray, Western Cape; J Morrison, Western Cape; A Puterman, Western Cape; E Zöllner, Western Cape; D Rhode, Western Cape. Pharmacotherapy - other therapies: A I Manjra (leader), KwaZulu-Natal; P M Jeena, KwaZulu-Natal; V Naidoo, KwaZulu-Natal; M Annamalai, KwaZulu-Natal; A van Niekerk, Gauteng.

Self-management plans: M Levin (leader), Western Cape; S Emanuel, Western Cape; D Hawarden, Western Cape; H Katz, Gauteng.

\section{Appendix B. Level of evidence}

IA Evidence from meta-analysis and randomised controlled trials

IB Evidence from at least one randomised controlled trial

IIA Evidence from at least one controlled trial without randomisation

IIB Evidence from at least one or other quasi-experimental study

III Evidence from non-experimental descriptive studies, such as comparative studies, correlation studies and case-controlled studies

IV Evidence from expert committee reports, opinions or clinical experience of respected authorities 
Appendix B. Grades of Recommendation Assessment, Development and Evaluation (GRADE)

\begin{tabular}{|c|c|c|}
\hline $\begin{array}{l}\text { Level of } \\
\text { recommendation }\end{array}$ & Quality of evidence & Definition \\
\hline A & High & $\begin{array}{l}\text { High-quality research very unlikely to change our confidence in the estimate effect based on } \\
\text { level I evidence }\end{array}$ \\
\hline B & Moderate & $\begin{array}{l}\text { Moderate-quality evidence, where future research is likely to have an important impact } \\
\text { on our confidence in the estimate effect. Based on level II evidence or extrapolated from } \\
\text { recommendations from level I evidence }\end{array}$ \\
\hline $\mathrm{C}$ & Low & $\begin{array}{l}\text { Low-quality evidence, where future research is likely to have an important impact on our } \\
\text { confidence in the estimate effect. Based on level III evidence or recommendations from level I } \\
\text { and II evidence }\end{array}$ \\
\hline D & Very low & $\begin{array}{l}\text { Very-low-quality evidence, where the estimate effect is uncertain. Based on level IV evidence } \\
\text { or recommendations from level I, II and III evidence }\end{array}$ \\
\hline
\end{tabular}

